How valid are these findings? As the study was based on a hospital rather than a community population there may have been some selection bias. St Mary's is near the hotels, but it is possible that some residents of bed and breakfast hotels in Paddington continued to attend maternity hospitals in their original distric of residence. Our definition of homelessness was restricted to women resident in a bed and breakfast hotel at booking. No data were available on the length of stay in the hotel or whether women were resident at conception. It is unlikely that women in their first pregnancy had conceived while resident in a hotel as pregnancy was usually the reason for placement. The study was therefore unable to look at the problems of pregnancy in the first trimester and early fetal loss. Three per cent of the women who were homeless at booking were rehoused during pregnancy, and it is possible that some of the housed population moved into temporary accommodation after they had booked for delivery, but such misclassification is likely to be small.

The characteristics of homeless populations vary as the boroughs placing people in hotels change; since this study the proportion of Bengali women has fallen. The findings of this study in 1988 may not be valid for 1990 and should be interpreted with caution in different populations.

The outcome of pregnancy in these women remains less good than that among the general population, but this seems to reflect their social deprivation rather than their place of residence. Obstetric care might be improved by earlier booking, which would allow the early detection and treatment of anaemia or other medical disorders, education about smoking, and assistance with obtaining appropriate social security benefits; an ultrasound scan could be performed at the optimal time of gestation. It is difficult to resolve the problem of late booking, but districts need to ensure that adequate information about local antenatal services is made available in social security offices and in the hotels known to accommodate these women. The placing district should also take responsibility for informing women of such services.

There has been much debate about the difficulty faced by the homeless people in registering with a general practitioner, ${ }^{1314}$ and because of this difficulty there is a greater onus on the hospital to provide comprehensive maternity care when needed. This may include providing interpreters and social workers.

Our study used routinely collected data to evaluate the obstetric outcome in homeless mothers. It was not able to consider the material and emotional experiences that have been described elsewhere. ${ }^{615}$ Despite this limitation it has shown an important application of the computerised maternity information system: to make possible the obstetric audit of specific subgroups of women who may be cause for concern.

We thank Mrs J Wadsworth for statistical advice, Mr D Paintin for advice on early drafts, and Professor R W Beard and Dr D Cunningham for their support. We also thank the midwives in North West Thames region for collecting the data that made this study possible.

\section{Department of the Environment. Homelessness statistics. London: HMSO, 1987. \\ 2 London Research Centre. Bed and Breakfast Information Exchange (BABIE) quarterly survey of temporary accommodation. London: Association of London Authorities/London Boroughs Association, 1988. \\ 3 Thomas A, Niner P. Survey of temporary accommodation. Homeless people placed in temporary accommodation. London: HMSO, 1989. \\ 4 Drennan V, Stern J. Health visitors and homeless families. Health Visitor 1986;59:340-2. \\ 5 Health Visitors Association, General Medical Services Committee of the BMA. Homeless families and their health, a joint report of access to primary health care by homeless families. London: BMA, 1989. \\ 6 Conway J, ed. Prescription for poor health: the crisis of homeless families. London: London Food Commission, Maternity Alliance, SHAC, Shelter, 1988. \\ 7 Audit Commission. Housing the homeless: the local authority role. Lond HMSO, 1989. \\ 8 Jarman B. Underprivileged areas: Validation and distribution of scores. Br Med f 1984;287:1587-92. \\ 9 London Research Centre. Homelessness survey in Bayswater. London: London Research Centre, 1988. \\ 10 Office of Population Censuses and Surveys. Infant and perinatal mortality 1988: district health authorities. OPCS Monitor 1989; No 3. (Series DH3.) \\ 11 Maresh M, Dawson AM, Beard RW. Assessment of an online computerised perinatal data collection and information system. Br $\mathcal{F}$ Obstet Gynaecol 1986;93:1239-45 \\ 12 Howie PW, Forsyth S, Ogston S, Clark A, Florey CV. Protective effect of breast feeding against infection. Br Med f 1990;300:11-6. \\ 13 Lowry S. Health and homelessness. Br Med f 1984;287:1587-92. \\ 14 Golding AMB. The health needs of homeless families. $7 \mathrm{R}$ Coll Gen Pract 1987;37:433-6. \\ 15 Bayswater Hotel Homelessness Project. Speaking for ourselves: families in Bayswater BE Bs. London: Bayswater Hotel Homelessness Project, 1987. \\ (Accepted 4 fune 1990)}

Department of Allergic

Diseases, University

Central Hospital, SF-00250

Helsinki, Finland

T Haahtela, MD, head of department

F Biörkstén, PHD, clinical chemist

Research Institute of Military Medicine, PO Box

50, SF-00301 Helsinki,

Finland

$\mathrm{H}$ Lindholm, $\mathrm{MD}$, consultant

L A Laitinen, MD, head of institute

General Headquarters, Finnish Defence Forces, PO Box 919, SF-00101

Helsinki, Finland

$\mathrm{K}$ Koskenvuo, MD, surgeon general of Finnish defence forces

Correspondence to: $\mathrm{Dr}$ Haahtela.

\title{
Prevalence of asthma in Finnish young men
}

T Haahtela, H Lindholm, F Björkstén, K Koskenvuo, L A Laitinen

\section{Abstract}

Objective-To determine the prevalence of asthma in cohorts of Finnish young men in the period 1926-89.

Design-A retrospective analysis using reports and statistics of Finnish defence forces.

Setting-Call up examinations of candidates for military conscription and examination of conscripts discharged because of poor health.

Subjects-Roughly 900000 men - that is, $98 \%$ of men of conscription age-examined in $1966-89$ and a proportional but unknown number examined in 1926-61.

Main outcome measures-Asthma recognised at call up examination, exemption from military service, and discharge from military service because of asthma.

Results -During 1926-61 the prevalence of asthma recorded at call up examinations remained steady at between $0.02 \%$ and $0.08 \%$. Between 1961 and 1966 , however, a continuous, linear rise began, the prev- alence increasing from $0.29 \%$ in 1966 to $1.79 \%$ in 1989-that is, representing a sixfold increase. Compared with 1961 the rise was 20-fold. From 1966 to 1989 the sum of exemptions and discharges from military service due to asthma increased analogously sixfold.

Conclusions-If the apparent increase in asthma detected in Finnish young men was due entirely to improved diagnostic methods and other confounding effects then some $\mathbf{9 5 \%}$ of cases must have gone undiagnosed in the years before 1966. This seems inconceivable, which suggests that much of the increase was real. This conclusion is strengthened by the observed rise in exemptions and discharges due to asthma.

\section{Introduction}

Reports from several countries suggest that the incidence and severity of asthma are on the increase. ${ }^{1}$ Much of the apparent increase, however, may be due to 
confounding effects such as changes in diagnostic fashion and improvements in detection. ${ }^{34}$ In this study we describe the prevalence of asthma in Finnish candidates for military conscription from 1926 onwards and examine the reality of the apparent increase.

\section{Subjects and methods}

In Finland $98 \%$ of all men have a medical examination at the age of 19 to establish their fitness for military service. Service is compulsory for those who qualify. Incapacitating asthma is an important cause of exemption from military service at call up and of discharge during military service.

Before 1972 the call up examination was carried out by local physicians appointed by the army. Since 1972 the medical examination has been carried out in two stages. Firstly, the candidate is examined by a local health centre physician with immediate access to records. Fitness is judged on the basis of history, a questionnaire completed by the examinee, and the findings of a clinical examination. When necessary the candidate is referred to a specialist for further evaluation. The man is re-examined at call up by the local physician during the autumn preceding the service year.

Since 1947 men have been placed in five categories of fitness (A-E) at the call up examination. Their state with respect to asthma is graded as: (A) no antiasthmatic treatment, normal lung function, not asthmatic, fit for service; (B) antiasthmatic treatment, normal lung function, asthmatic but fit for service; (C) to (E) antiasthmatic treatment, decreased lung function, exempted from military service by virtue of asthma of varying severity.

During 1966-89 roughly 900000 men were examined. The number examined in 1926-61 was not available but was in proportion - that is, roughly $98 \%$ of men of conscription age. Military service has been for eight to 11 months since the 1940s. Service usually begins at the age of 20 .

\section{Results}

The figure shows the prevalences of asthma among

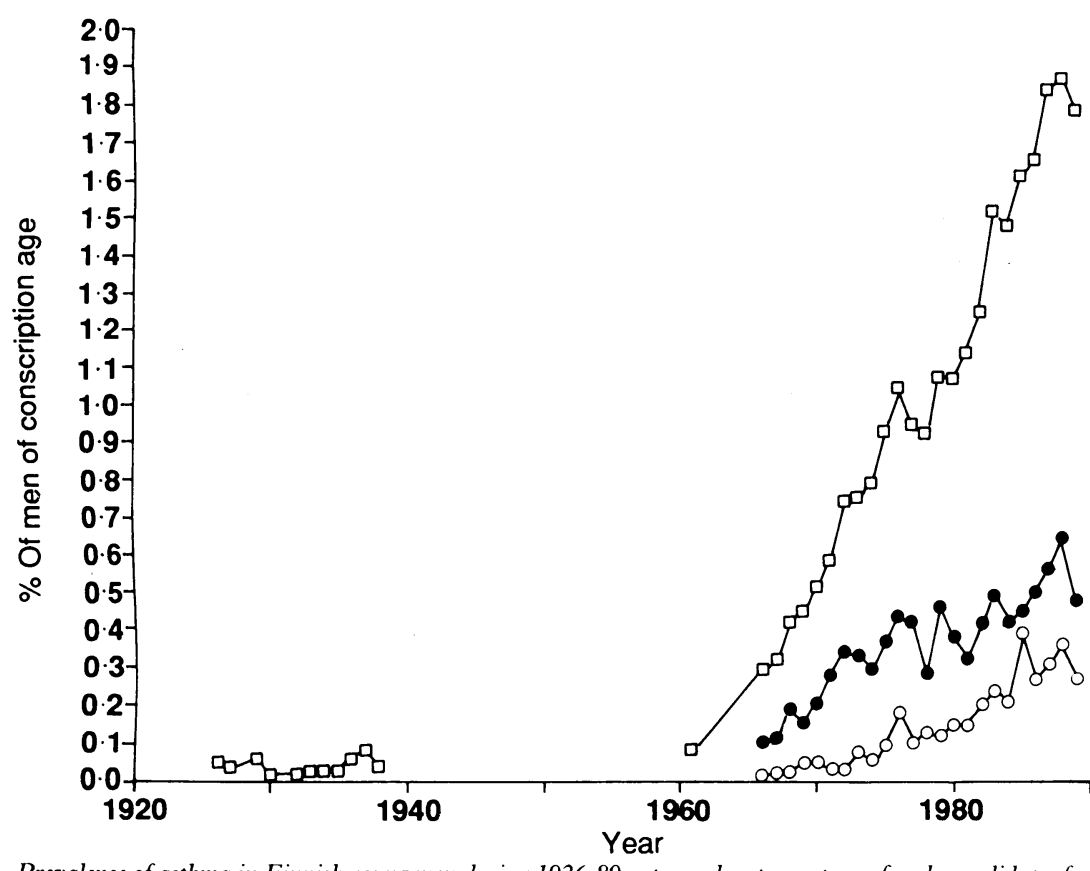

Prevalence of asthma in Finnish young men during 1926-89 expressed as percentage of male candidates for military conscription with diagnosis of asthma at or before call up medical examination $(\square)$, percentage of men exempted at call up for military service by virtue of disabling asthma (-), and percentage of conscripts discharged during course of military service because of asthma $(\bigcirc)$ men of conscription age during the study years for which statistics were available. Between 1926 and 1939 the prevalence of asthma at call up remained steady at between $0.02 \%$ and $0.08 \%$. In 1961 the rate was still $0.08 \%$. A rise in prevalence seemed to have begun somewhere between 1961 and 1966.

From 1966 systematic statistics were available, and from that date the prevalence of asthma recorded at the call up examination had risen continuously. The curve was roughly linear. The prevalence increased from $0.29 \%$ in 1966 to $1.79 \%$ in 1989 - that is, representing a sixfold rise. Compared with 1961 the rise was 20 -fold. The change in the medical examination system in 1972 had no noticeable effect.

Men with asthma considered to be incapacitating at the call up examination are exempted from military service. Nevertheless, despite an increasing number of exemptions the numbers of men who entered service only to be discharged later because of asthma had also risen. When the years 1966 and 1989 were compared the proportion of men with a diagnosis of asthma at call up, the proportion exempted from military service because of disabling asthma, and the proportion discharged during military service because of asthma had risen sixfold, fivefold, and 14-fold respectively. The proportions of men exempted for all other somatic causes were $4 \cdot 6 \%$ in $1966,7 \cdot 5 \%$ in 1976 , and $5.4 \%$ in 1986.

\section{Discussion}

The substantial increase in asthma detected by this study raises questions about the comparability of data for various years. In particular, Are prevalence data from before 1966 dependable? Are asthma rates below $0 \cdot 1 \%$ credible? Plainly asthma as defined now frequently remained undiagnosed or was labelled differently in the past. Even so, the stable, less than $0 \cdot 1 \%$ prevalence recorded from 1926 to 1961 was remarkable. It must mean that incapacitating asthma - which could hardly escape notice-was rare in young men. Later statistics are more dependable, particularly as data on the number of men exempted at call up and discharged during service because of asthma are available. Basic military training in Finland is strenuous for most conscripts and may be regarded as an exercise tolerance test which should lead to the detection of any incapacitating asthma that had not been detected before.

An increasing trend in the prevalence of asthma at call up became evident in 1966. Subsequently the increment in prevalence remained fairly constant at around $0.07 \%$ a year, so that by 1989 the prevalence had reached $1 \cdot 79 \%$. Somewhat higher rates have been noted in Swedish conscripts; the prevalence of asthma in 1971 was $1.9 \%$ and in $19812 \cdot 8 \%$, suggesting a yearly increment of $0.09 \%$.

Our impression that asthma rates are rising is strengthened by the proportions of men exempted from military service or discharged in the course of service because of asthma. The sum of these proportions was $0 \cdot 12 \%$ in 1966 and $0.75 \%$ in 1989 . In the same period there was little change in exemptions from all other somatic causes. We do not believe that the apparent rise in the prevalence of asthma is due to changing requirements for fitness in the Finnish army.

If we assume that the increase in asthma recorded at call up is entirely due to improved diagnostic methods and other confounding effects then some $95 \%$ of cases must have gone undiagnosed or been labelled differently before 1966 . We find this inconceivable and consider that much of the increase is real. Our conclusion is supported by the similar steep rise in exemptions and discharges from military service due to 
incapacitating asthma. It is quite improbable that a substantial portion of the observed increase in disabling asthma could be artefactual.

1 Anderson HR. Is the prevalence of asthma changing? Arch Dis Child 1989;64:172-5

2 Fleming DM, Crombie DL. Prevalence of asthma and hay fever in England and Wales. Br Med F 1987;294:279-83.
3 Hill R, Williams J, Tattersfield A, Britton J. Change in use of asthma as a diagnostic label for wheezing illness in schoolchildren. Br Med $\mathcal{J} 1989$; 99:898

4 Littlejohns P, Ebrahim S, Anderson P. Prevalence and diagnosis of chronic respiratory symptoms in adults. Br Med 7 1989;298: 1556-60.

Aberg N. Asthma and allergic rhinitis in Swedish conscripts. Clin Exp Allergy 1989;19:59-63

\section{Double blind placebo controlled trial of pulse treatment with methylprednisolone combined with disease modifying drugs in rheumatoid arthritis}

T $M$ Hansen, P Kryger, H Elling, D Haar, $M$ Kreutzfeldt, $M$ W Ingeman-Nielsen, A T Olsson, C Pedersen, A Rahbek, N Tvede, J Winge

\section{Abstract}

Objective-To assess whether monthly treatment with intravenous methylprednisolone enhances or accelerates the effect of disease modifying drugs in patients with rheumatoid arthritis.

Design-A 12 month double blind, placebo controlled, multicentre trial in which patients with active rheumatoid arthritis were randomly allocated to receive pulses of either methylprednisolone or saline every four weeks for six months. At the start of the pulse treatment all patients were started on penicillamine or azathioprine.

Setting-Four rheumatology departments in Denmark.

Patients - 97 Patients (71 women, 26 men) aged 23-84 (mean 60) who had active rheumatoid arthritis of at least four weeks' duration despite treatment with non-steroidal anti-inflammatory drugs.

Main outcome measures-Monthly clinical recording of morning stiffness, number of tender and swollen joints, blinded observers' evaluation of therapeutic effect, and patients' self assessed condition. Concomitant laboratory measurements of erythrocyte sedimentation rate and concentrations of $\mathrm{C}$ reactive protein and haemoglobin. Radiography to determine the number of erosions at the start of treatment and after 12 months.

Results -57 Patients completed the trial, taking the same disease modifying drug throughout. Evaluation four weeks after each pulse treatment and at 12 month follow up showed no significant differences between the methylprednisolone and placebo groups in any of the clinical or laboratory variables. Radiography showed the same degree of progression of erosions in both groups. Evaluation of the total data on 97 patients and on the 57 who completed the trial showed the same lack of significance between the treatment groups.

Conclusions-Intravenous pulse treatment with steroids can be recommended only for rapid temporary relief of flares of disease in patients with rheumatoid arthritis. The response is short lived. Repeated pulses of methylprednisolone at four week intervals do not improve the results of treatment with drugs that induce remission such as penicillamine and azathioprine.

\section{Introduction}

Several studies have described a significant short term improvement in the symptoms of patients with rheumatoid arthritis after pulse treatment with methylprednisolone. The mean duration of response of clinical variables has been reported to be four to 10 weeks, with a few people responding for longer. ${ }^{1.3}$
The lack of sustained benefit and the reported equivalent effects of high doses of oral steroids indicate that pulse treatment with steroids is not suitable for long term treatment of rheumatoid arthritis. Recent reports, however, have advocated the use of pulse treatment with steroids in combination with disease modifying drugs. The pulse treatment seems to accelerate and increase the delayed response to these drugs. ${ }^{5}$

Most of the evidence of the benefit from pulse treatment with methylprednisolone comes from uncontrolled studies. ${ }^{56}$ We report the results of a randomised double blind study on the effect of monthly pulses of methylprednisolone in patients with rheumatoid arthritis starting to take disease modifying antirheumatic drugs

\section{Patients and methods}

The study was designed as a 12 month double blind trial with a placebo control group and included patients attending four rheumatology departments.

\section{PATIENTS}

We studied 97 patients ( 71 women, 26 men; age range $23-84$, mean 60 ) with definite or classic rheumatoid arthritis as defined by the American Rheumatism Association of $0-43$ (mean 9) years' duration. All the patients had had active disease for at least four weeks despite having been treated with non-steroidal antiinflammatory drugs. Active disease was defined by the presence of at least three of the following criteria: six or more tender joints, three or more swollen joints, morning stiffness lasting $\geqslant 45$ minutes, and erythrocyte sedimentation rate $>28 \mathrm{~mm}$ in the first hour.

Patients in functional class IV according to the American Rheumatism Association criteria and those who had received intra-articular or oral treatment with glucocorticosteroids within six weeks before the start of the study were excluded.

Informed consent according to the Helsinki II declaration was obtained from all patients. The study was approved by the local ethical committee.

\section{TREATMENT}

A statistician randomly allocated blocks of 10 patients in each centre to pulse treatment with either 15 mg methylprednisolone/kg body weight or saline. Each centre received sealed numbered envelopes containing information about the nature of the pulse treatment. The envelopes were opened and the patients started on the treatment in numerical order.

Every four weeks for a total of six times (weeks 0 , $4,8,12,16$, and 20) the patients in the trial group were given an intravenous infusion of methylprednisolone

\section{Dr Kryger.}

BMJ VOLUme 301

4 AUgust 1990 